\title{
SIX-SIGMA BASED APPROACH FOR PRODUCTIVITY IMPROVEMENT IN CONSTRUCTION PROJECTS
}

\author{
Seung Heon Han, Ph.D. ${ }^{1}$, Ho Dong Ryu ${ }^{2}$, Myung Jin Chae, Ph.D., P.E. ${ }^{3}$, \\ Han Him Kim ${ }^{4}$, Do Yon Kim ${ }^{5}$, Sun Hee Kim ${ }^{6}$ \\ ${ }^{1}$ Associate Professor, ${ }^{2}$ Graduate Student, \\ ${ }^{3}$ Researcher, ${ }^{4}$ Researcher, ${ }^{5}$ Researcher, ${ }^{6}$ Researcher \\ Dept. of Civil Engineering, Yonsei University, Seoul, Korea \\ shh6018@yonsei.ac.kr
}

\begin{abstract}
In order to improve the productivity of construction projects and achieve reliable workflow, it is necessary to quantify the eventual goals for the target process assessment. This research explores the feasible solutions for the construction performance improvement by use of the six-sigma principle, which provides appropriate boundaries of controlling critical sources of the variability. Then, a case study is performed with an aid of a simulation tool toward the end of this paper.
\end{abstract}

Keywords: performance, six-sigma principle, variation control, buffer size, simulation

\section{INTRODUCTION}

In the pursuit of the construction productivity, it is important to ensure the quality of work processes and improve the overall performance. There have been a number of construction productivity improvement techniques such as lean production, just-in-time, pullscheduling, last planner, etc. However, most of the results fell short of our expectations due to the lack of practical techniques in estimating the defect rates of production activities.

In order to estimate the defect rates in reasonably fast and accurate manners, this research introduces the six-sigma principle which is known as the innovative process management strategies at a corporate level in the manufacturing industry. The six-sigma principle may also be applied to construction projects. In construction industry, the use of the six-sigma principle for the performance assessment has started to appear early in 2000. However, the researches so far have been limited to the descriptions of the sixsigma principle and almost no project-oriented construction case study has been reported. This study focuses on the development of the general methodology of using six-sigma principles for construction projects in terms of the productivity improvement and the methodology. This has been verified through a case study.

Many researchers have so far developed various techniques for operation process improvement. Being partly and individually adopted for specific aims, they have been strategically utilized in combination with one another and recently are being designed to realize the innovative lean process. However, the techniques actually place their focuses more on effectiveness in the process of achieving project goals than on efficiency which has been an important issue in traditional production systems. This impedes our full grasp of definite distinction of the newly emerged notion, that is to say, the pursuit of process effectiveness from the existing efficiency-oriented consideration.

Typical construction work is so fragmented that it needs to be performed in accordance with a predetermined schedule. For this reason, the highest priority is placed on the cost and time reduction using resource optimization techniques. It might be difficult to improve the process effectiveness without a substantial performance improvement through ensuring the process efficiency. Furthermore, a reasonable quantitative indicator for the performance improvement is needed to help the field manager set out a definite goal. The performance indicator also motivates field managers for the process improvement.

Since construction projects are not repetitive while manufacturing industry has stable and repetitive processes, it is required to understand the differences in applying the six-sigma principles.

It is noticed that the assembling process is found in both manufacturing and construction work. In this research, an assembling process has been chosen as a sample application to the lowest-level activities and the noticeable findings are presented.

Three phases are presented in this research: (1) strategy and procedure development for applying the six-sigma principle; (2) experimental investigation through the simulation with a real case; and (3) discussions on practical advantages of the six-sigma application to the construction process. 


\section{THE CONCEPT OF SIX-SIGMA}

Recently, customer satisfaction has never been recognized as important as before. High quality (lowdefect) products are the key for the customer satisfaction. The corporate-level efforts for maintaining low and stable defect rate become a major issue of the company-wide marketing strategy. The discussion on six-sigma as one of these tools, is vigorously going on in order to meet overall customer satisfaction through achievement of nearperfection in product by using statistical methodologies. The conceptual diagram of six-sigma quality control is presented in Figure 1. If normal value for a process is located at the midpoint between upper and lower limit, each one is $6 \sigma$ away from the normal value. In short, the range of no defect is $\pm 6 \sigma$ from the normal.

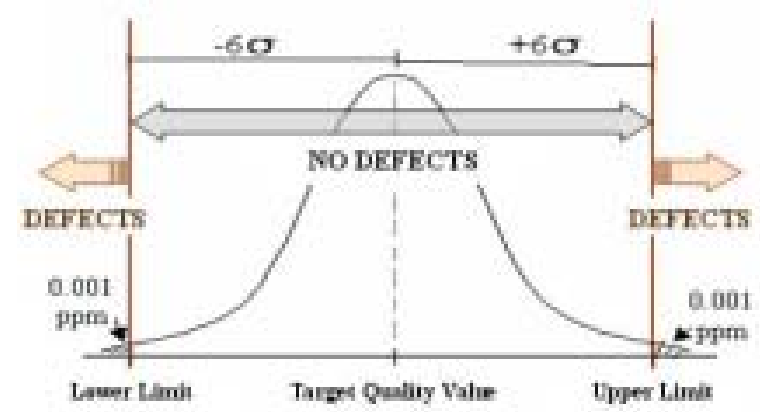

Figure 1. The Concept of Six-sigma

The six-sigma movement is to begin with setting sixsigma quality as a company-wide goal and to implement it through utilizing the necessary tools for reaching it.
The six-sigma movement is to begin with setting sixsigma quality as a company wide goal and to implement it through utilizing the necessary tools for reaching it. The meaning of defect, which was confined just to a product containing a flaw in manufacturing sector, is recently being extended to a variety of industries such as customer dissatisfaction in service industry or accuracy level of documentation in office, and the scope of quality management sigma is also expanding to include not only quality control but also six sigma management (Ahn et al. 2000). Six-sigma initiatives are implemented through DMAIC (Define, Measure, Analysis, Improvement, Control) problem-solving framework in Table 2.

As discussed above, existing (general) methods for improving work processes include many problems in improving productivity of construction projects, but six-sigma, on the other hand, is a statistical approach that enables to set a sigma level as a goal to achieve, and to take action accordingly. To date, construction industry has shortcomings in systemically managing productivity and other performance indicators, and setting the clear objective of improving them, which, in addition, has contributed to limitations to process innovation in the construction site.

Accordingly, in an attempt to overcome these limitations, construction industry needs to utilize sixsigma principles and pursue process innovation systematically and statistically. Due to many large scale projects in construction industry, sophisticated variation management is required in order to ensure conformance to project requirements including safety, quality and duration. Therefore, six-sigma, the objective data-based and statistical methodology, can show greater effects on management of such main indicators in construction than other industries.

Table 1. DMAIC Framework

\begin{tabular}{|c|c|c|}
\hline Phase steps & Step description & Associated tools and techniques \\
\hline Define & What problem needs to be solved? & Process mapping, brainstorming \\
\hline Measure & $\begin{array}{l}\text { What is the problem? } \\
\text { What is the current performance? }\end{array}$ & $\begin{array}{l}\text { Pareto chart, control chart, } \\
\text { process sigma calculation }\end{array}$ \\
\hline Analyze & When, where and why do defects occur? & Cause and effect diagram, benchmarking \\
\hline Improve & How can the problem be solved? & $\begin{array}{l}\text { Regression analysis, multi-variable chart, } \\
\text { cost analysis }\end{array}$ \\
\hline Control & $\begin{array}{l}\text { How the sustainable quality } \\
\text { improvement can be done? }\end{array}$ & $\begin{array}{l}\text { Institutionalization of the improved process } \\
\text { Process monitoring for continuous process } \\
\text { improvement }\end{array}$ \\
\hline
\end{tabular}




\section{STRATEGY FOR SIX-SIGMA IMPLEMENTATION}

Different from manufacturing industry, fragmented and project-oriented work processes are unique to construction industry. For successful application of six-sigma, construction industry needs its own strategy for successful implementation of six-sigma.

\subsection{Integration of six-sigma and other innovative methodologies}

For successful application of six-sigma, construction industry needs to clearly define strong and weak points of existing techniques for process innovation. It is necessary to maintain their advantages, which make the established infrastructure and strategies reused, and to overcome limitations through employing new concepts. Steel Case, Co., U.S.-based company, achieved improvements in cost, quality, and time reduction in cost and through incorporating lean manufacturing system and statistical tools for improvement in manufacturing process (Steel Case Corp., 2002). In addition, Kroslid(2001) concluded that integration of both lean and six-sigma can result in better performance. Kroslid also emphasized integration of lean manufacturing system and sixsigma principles including implementation steps (DMAIC) through case study. Lean construction, therefore, can show better accomplishment when combined with six-sigma concepts.

\subsection{Phased application of six-sigma}

Unlike the manufacturing process, many construction activities are being done at large open land. In addition, they have more uncertainties in spite of repetitiveness in work process. Therefore, it is important to select the work process similar to a manufacturing process which is usually sensible enough to reflect the impact from adjustment of process orders, resource level, etc. Prudent and systemized approach is required in selecting an activity applied to six-sigma concepts.

This research suggests two steps to the phased application of six-sigma. The first one of two steps deals with processes similar to ones of manufacture such as assembling works which are main parts of the plant construction or the equipment installation projects. The second step includes more complicated construction process than process similar to manufacture's. Second step needs a discreet and careful attitude in applying six-sigma.

Performance measurement system is one of the most important support systems for deploying six-sigma concepts through construction processes. Prior to adopting six-sigma, construction companies should design their own basic strategies and policies in consideration of their conditions.

In determining the performance indicators for six- sigma application, it is required to consider the distinction between not only those of each process but also key factors critical to project success for each construction phase. At this time, six-sigma methodologies are aiming at the broad process improvement and are required to select the process related to the subject CTQ in order to avoid interrupting the continuous effect of process improvement not only those of each process but also key factors critical to project success for each construction phase. At this time, six-sigma methodologies are aiming at the broad process improvement and are required to select the process related to the subject CTQ in order to avoid interrupting the continuous effect of process improvement.

CTQ (Critical Total Quality) means the key qualityinfluencing element and the most related element to a process performance indicator in fact. For instance, if productivity is used as its performance indicator, the reliability of resource flow can be set as a main CTQ due to the closest association with productivity. Generally, the mean and standard deviation of collected data are calculated, and then the present sigma level of the process is measured according to the defined performance standard after determination of process capability index $\mathrm{C}_{\mathrm{P}}$ with assumption of no skewness in data.

\section{$C_{p}($ process capability index $)=\frac{U S L-M E A N}{3 \times S T D E V}$ \\ If only USL given, $\sigma($ sigma level $)=3 \times C_{p}$ \\ where USL: upper specification limit \\ Mean: the mean of the data \\ STDEV: the standard deviation of the data}

\subsection{Basic Framework for the Six-sigma-based Management}

The six-sigma concept can be appropriately employed to the construction process control within the basic framework, as shown in Table 2, which is developed upon the previous fundamental researches. Closely associated with the existing techniques for the manufacturing process improvement, the sixsigma-based management is applied in construction projects according to the strategies as depicted in the preceding sections. We repeat the consecutively organized steps of defining, measuring, analyzing and adjusting the input values so as to enhance the indices of process performance quality by continuously monitoring the outcomes and identifying potential problem areas.

Considering the highly uncertain attributes immanent in construction processes, it is not so a practical way that the six-sigma level is strictly adopted for all cases when we control the variability of the abovespecified factors directly linked to process performance within a fixed narrow range. Provided 
with quantitative goals by the degree of the sigma level, therefore, proceeding with relevant efforts of process assessment and management, as such, need to be more emphasized than attaining the six-sigma quality. On the other hand, to describe important topics we consider last but not least when the general six-sigma application procedure, DMAIC, is imported into the construction process management, its special characteristics different from other industries should be fully incorporated at each phase.

Table 2. Basic Framework for the Six-sigma Application to Construction Projects

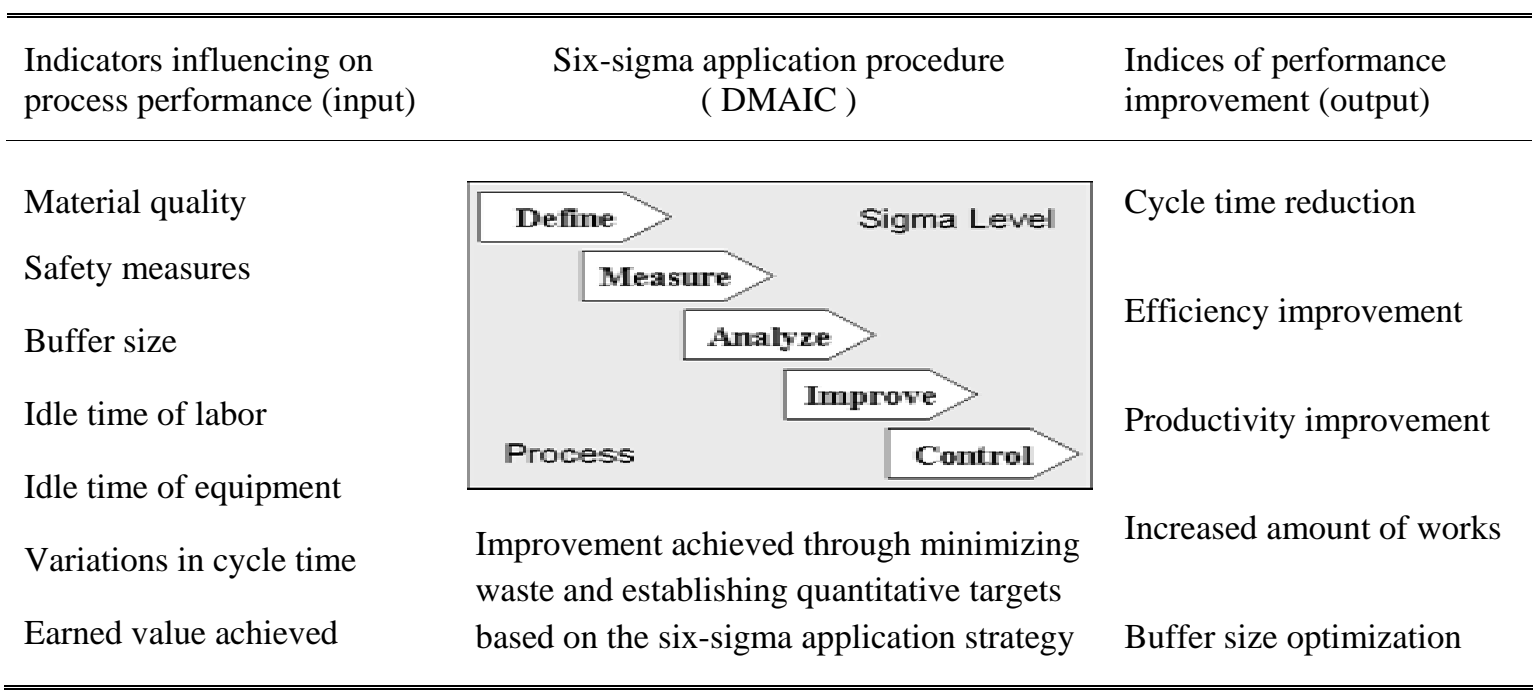

\section{CASE STUDY: Iron-reinforced-bar Assembling Process}

To demonstrate the advantages of the six-sigmabased management strategy suggested in the previous section, we targeted an assembly work at the lowest level of an entire construction process and did comparative analyses of its performance improvement with an aid of a simulation tool. Among the power line construction was an iron-reinforcedbar assembling process selected for the case study, and EXTEND ${ }^{\mathrm{TM}}+\mathrm{BPR}$ was employed to develop the simulation models.

\subsection{Definition of CTQ}

In this case, productivity improvement level was set as the principal indices of process performance quality to begin with. Then, we identified the factor which is most closely linked with productivity by observing process variations. Through a repeated analyses with various independent variables, the degree of variations in work process cycle time was found to be as CTQ.

Subsequently, it was needed to determine the target CTQ in order to evaluate the current process status and establish the improvement goal. Figure 2 displays the cycle time variations for a relatively long period of the assembly works. Reasonably guessing from this distribution with some extraneous points taken into account, we fixed 40 minutes as the target CTQ to achieve a desirable productivity.

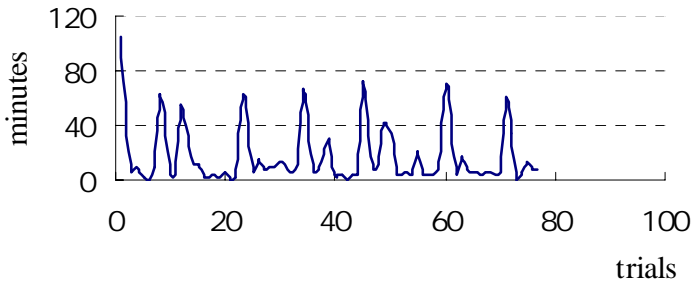

Figure 2. Cycle Time Variations

Based on the target CTQ, we found from the equations (1) and (2) that the current defect rate which assumes the possibility of cycle time over 40 minutes was represented as 1.41-sigma level. This is yet far below the six-sigma level, thus it is required to set up the strategies to improve work flows and accordingly enhance the process reliability.

$$
\begin{aligned}
& C_{p}=\frac{U S L-M E A N}{3 \times S T D E V}=\frac{40-17.46}{3 \times 16}=0.47 \\
& \sigma=3 \times C_{p}=1.41
\end{aligned}
$$

On the other hand, further analyses revealed the buffer size had the most critical influence on the assembly work cycle time. Therefore, through the buffer size optimization we improve the sigma level in CTQ and make progress in the entire process performance. 


\subsection{Improvement of CTQ}

The improvement has achieved in two phases: (1) the improvement by the modification of the assembling process; (2) the improvement by the resource buffer size optimization.

Before the process modification and resource optimization, the resource level was 8.4 , and sigma level was 1.41. After the process modification (Column 1 and 2 of Table 3) productivity has improved by 0.003 while sigma level reached only 1.72 , which is not a sufficient improvement both in terms of productivity and sigma level.

After the buffer size optimization, the targeted result (six-sigma level) has been obtained. By increasing the buffer size from 11.5, 14.5, and 19.2, the productivity has improved to $0.055,0.06$ and 0.061 , respectively. Sigma level has also improved as high as 6 when the buffer size is 19.2. However, the productivity has risen by only 0.001 by adding 4.7 resource unit and 1700 cost unit.

Therefore, it is suggested that 14.5 is the most economic buffer size, maintaining reasonable productivity and sigma level.

Table 3. Performance Index by Buffer Size

\begin{tabular}{lrrrrr}
\hline \hline \multirow{2}{*}{ Item } & \multicolumn{5}{c}{ Buffer Size (ton) } \\
\cline { 2 - 6 } & 8.4 & 8.4 & 11.5 & 14.5 & 19.2 \\
\hline $\begin{array}{l}\text { Productivity (ton/min) } \\
\text { Total Cost (\10,000) }\end{array}$ & 0.049 & 0.052 & 0.055 & 0.06 & 0.061 \\
$\begin{array}{l}\text { Additional Cost } \\
(\backslash 10,000)\end{array}$ & 350 & 350 & 550 & 720 & 885 \\
$\begin{array}{l}\text { Throughput (ton) } \\
\text { Cycle Time (min) }\end{array}$ & 236 & 252 & 268 & 288 & 290 \\
$\begin{array}{l}\text { Cycle Time } \\
\text { Sigma Level }\end{array}$ & 162 & 150 & 154 & 159 & 160 \\
& 1.41 & 1.72 & 2.58 & 3.64 & 6 \\
\hline \hline
\end{tabular}

\subsection{Result Analysis}

According to the simulation results that depicted fluctuations in the sigma level, the process reliability in terms of variations in the various performance indices can be evaluated in the midst of productivitycost tradeoff relationships and about 20 tons of the total material stock is required to last during the targeted assembling work period in order that the process cycle time should not lapse into excessive volatility which assumes the defect rate of not reaching the degree of the six-sigma level. However, there exist spatial limitations to the sufficient inventory status and furthermore the maintenance cost escalates as the storage volume grows, thus it is recommended that we regulate the storage between
14.5 and 19.2 tons so as to have the work efficiency remain as high as the process reliability is attained to a satisfactory level.

The graph that describes the relationship of the sigma level in CTQ and productivity appears in Figure 3. We can find out the productivity gradually improves while the cycle time variation ranges are getting narrower from the 40-minute width which was set as a standard performance measuring criterion and it is also observed that around the 4 sigma level the improvement comes to its upper limit achievable through the control of variability in CTQ.

To confirm this phenomenon from a different point of view, Figure 4 suggests the simulated plotting of the material storage-productivity relationship, which takes on almost the same curved shape as that in Figure 3.

On the other hand, Figure 5 graphically shows the linear incremental relationship between the storage and the cost. This trend being compared with the previous results as to the process efficiency improving aspects, it is necessary to assess the optimum inventory level where we can expect a desirable productivity at a reasonable expense.

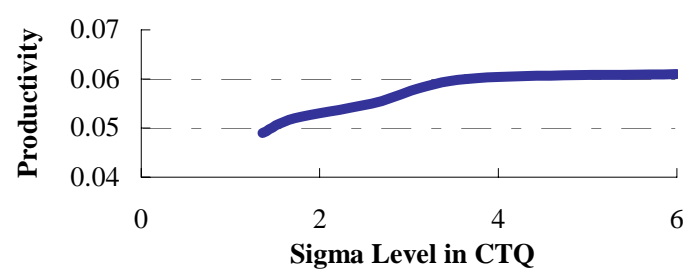

Figure 3. Relationship between Sigma Level in CTQ and Productivity

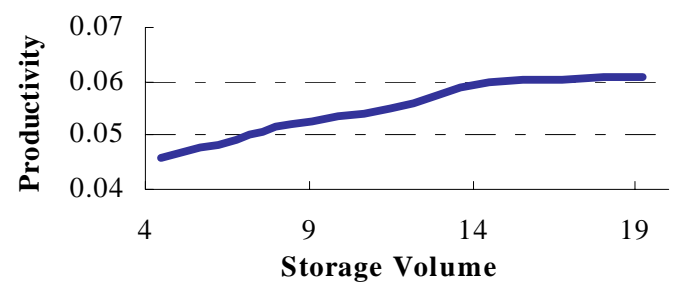

Figure 4. Relationship between Storage Volume and Productivity

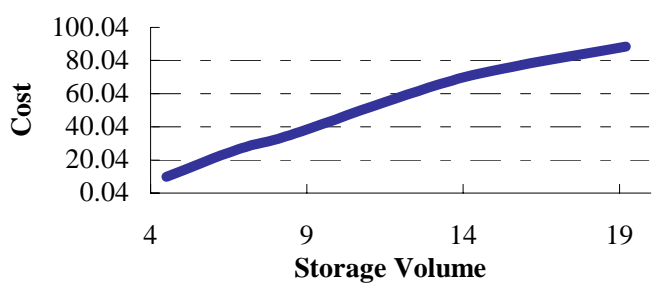

Figure 5. Relationship between Storage Volume and Cost 
We have concluded that the six-sigma-based management strategy can allow more enhanced benefits in real process improvement than do the existing techniques. The former provides especially a definite objective of the six-sigma level to ongoing process managerial measures while the latter requires quantifiable criteria to proceed with additional improvements.

\section{CONCLUSIONS}

The six-sigma concept is a corporate-level innovative management discipline currently prevalent in the manufacturing industry. This research explored the reasonable strategies for the improvement of construction process and productivity by combining the six-sigma with the idea of lean construction.

In-depth comparative analysis was done on the existing methods for performance improvement and the advantages of the six-sigma principle over the traditional techniques were identified. Subsequently, a basic scheme promoting the practical applications of the six-sigma concept to construction projects was suggested along with a general framework incorporated with the strategies. Then, according to the proposed procedure of the six-sigma applications, the existing process was improved in various ways through a case study of the standard unit activity groups.

The improvement levels targeted for the variations in the amount of resources and the indicators of work process performance were set in terms of the sixsigma concept. Consequently, with the help of computer simulations, the overall construction performance improved as the degree of sigma level advanced through the control of CTQ.

As a result, it is concluded that the six sigma principle has brought more benefits in generating the optimized solution sets from initial performance indices as the target processes become complicated and extended.

In order to enhance the practical effectiveness of the six-sigma-incorporated strategy, it is required that various aspects of the process should be studied using more generic construction project cases for a long period of time. The framework suggested in this study can be continuously enhanced in accordance with resulting performance by differing input variables. Furthermore, the systematic guidelines on the CTQ control of various target factors need to be developed based on the diverse characteristics of various companies because the customization of the six-sigma strategy facilitate construction firms to achieve their own process evaluation paradigm.

To achieve the aforementioned objectives, an advanced methodology for the financial feasibility analysis should be developed before the implementation of the six-sigma principle to a real project. It will provide the basis on which the improvement targets can be selectively chosen based on the practical benefits.

Consequently, an integrated management system should be established to regulate the variations of all the process constituents through the overall performance quality assessment.

\section{Acknowledgments}

The writers thank Kyung-Ho Chin of Korean Institute of Construction Technology for providing the data used in this research and all colleagues who have offered constructive criticism of this work as it progressed.

\section{REFERENCES}

[1] Abdelhamid, T. S., "Six-Sigma in Lean Construction Systems: Opportunities and Challenges", Proceeding, The 11th Annual Conference for Lean Construction, 22-24 July 2003, Blacksburg, Virginia, pp. 65-83, 2003.

[2] Al-Sudairi, A., "Evaluation of construction process: Traditional Practice Versus Lean Principle", Ph.D Thesis, Dept. of Civil Eng, The Univ. of Colorado at Boulder, 2000.

[3] Ballard, G., "Lean Project Delivery System", White Paper No.8, Lean Construction Institute, California, 2000.

[4] Buggie, F. D., "Beyond Six Sigma", Journal of Management in Engineering, ASCE, Vol. 16, No.4, pp. 28-31, 2000.

[5] Kroslid, D., "Six Sigma and Lean ManufacturingA Merger for World-class Performance, but is it Really Talking Place?", The Asian Journal on Quality, Vol.2, No.1, pp. 87-104, 2002.

[6] Howell, G. and Ballard, G., "Implementing Lean Construction: Understanding and Action", Proceeding, The 6th conference of the International Group of Lean Construction, Guaruja, SaoPaulo, Brazil, 1998.

[7] Thomas, H. R. and Horman, M. J. and Souze, U. E. and Zavrski, I., "Reducing Variability to improve Performance as a Lean Construction Principle", Journal of Construction Engineering and Management, ASCE, Vol. 128, No.2, pp. 144154, 2002.

[8] Thomas, H. R. and Horman, M. J. and Souze, U. E. and Zavrski, I., "Improving Labor Flow Reliability for Better Productivity as Lean Construction Principle", Journal of Construction Engineering and Management, ASCE, Vol. 129, No.3, pp. 251261, 2003. 
[9] Hammer, M., "Reengineering work: Don't automate, Obliterate", Harvard Business Review, pp. 104-112, 1990.

[10] Pheng, L. S. and Chuan, C. J., "Just-In-Time Management of Pre-cast Concrete Components", Journal of Construction Engineering and Management, ASCE, Vol. 127, No.6, pp. 494-501, 2001.

[11] Cheng, M. Y. and Tsai, M. H., "Reengineering of Construction Management Process", Journal of Construction Engineering and Management, ASCE, Vol. 129, No.1, pp. 105-114, 2003.

[12] Yasuhiro, M., "Toyota Production System", Institute of Industrial Engineers, 1994. 